\title{
CLASSES EXPERIMENTAIS BAIANAS E A QUEBRA DE PARADIGMAS CURRICULARES: do programa de matemática à prática educativa nas décadas de 1960 e 1970
}

\author{
Mariana Moraes Lôbo Pinheiro' \\ Marco Antonio Leandro Barzano2
}

\section{RESUMO}

As classes experimentais baianas foram parte do projeto de modernização do ensino desenvolvido durante as décadas de 1960 e 1970. Coordenadas pelo CECIBA em época de Ditadura Militar no Brasil, cumpriram importante meta de difundir uma proposta de ensino (de Matemática) mais inovador, principalmente, no que diz respeito a conteúdos e métodos de ensino utilizados. As experiências realizadas em diferentes escolas de Salvador foram palcos de testes de novos programas e estratégias de ensino, mobilizando saberes a ensinar e para ensinar (HOFSTETTER; VALENTE, 2017) naquele contexto de experimentação pedagógica. Estes saberes, oriundos, principalmente, de cursos de aperfeiçoamento para professores, oferecidos pelo CECIBA, foram analisados, a partir das narrativas disponibilizadas em entrevistas semiestruturadas fornecidas por professores e alunos envolvidos na experiência do Colégio Estadual Luiz Pinto de Carvalho. Pretendemos discutir neste artigo, portanto, como as classes experimentais baianas, constituídas por uma iniciativa de transformação curricular a partir da institucionalização da Matemática Moderna, representaram um período de avanços no ensino (de Matemática) com repercussões importantes na vida dos personagens envolvidos. Trata-se de uma pesquisa qualitativa, que toma como referenciais a perspectiva de história cultural de Chartier (1990), aliada à concepção de solidariedade (RORTY apud ASSIS, 2013) e à ideia de experiência (LARROSA, 1994).

Palavras-chave: Classes experimentais. Inovação curricular. Matemática Moderna.

\footnotetext{
1 Doutora em Ensino, Filosofia e História das Ciências (UFBA/UEFS). Professora Substituta do Departamento de Educação II - Faculdade de Educação da Universidade Federal da Bahia. Orcid iD: https://orcid.org/0000-0001-5388-5162. Email: pinheiromml@gmail.com

2 Doutor em Educação (UNICAMP). Professor Titular (UEFS). Professor do Programa de PósGraduação em Ensino, Filosofia e História das Ciências (UFBA/UEFS). Professor do Programa de Pós-Graduação em Educação (UEFS). Orcid iD: https://orcid.org/0000-0003-3273-9216. Email: marco.barzano@gmail.com
} 


\title{
BAIAN EXPERIMENTAL CLASSES AND THE CHALLENGE OF CURRICULAR
}

\section{PARADIGMS: from the mathematics program to educational practice in the}

\author{
1960s and 1970s
}

\begin{abstract}
The experimental classes in Bahia, were part of the modernization project of teaching developed during the 1960s and 1970s. Coordinated by CECIBA during a Military Dictatorship in Brazil, they fulfilled an important goal of disseminating a more innovative teaching (Mathematics) proposal, especially in the which concerns content and teaching methods used. The experiments carried out in different schools in Salvador have been used to test new programs and teaching strategies, mobilizing knowledge to teach and for teaching (Hofstetter; Valente, 2017) in that context of pedagogical experimentation. These knowledges, mainly coming from teacher improvement courses offered by CECIBA, were analyzed from the narratives provided in semistructured interviews provide by teachers and students involved in the experience of Luiz Pinto de Carvalho State College. We intend to discuss in this article, therefore, how the Bahian experimental classes, constituted by an initiative of curricular transformation from the institutionalization of Mathematics Modern, represented a period of advances in teaching (of Mathematics) with important repercussions in the life of the characters involved. It's a qualitative research that takes as reference the perspective of cultural history of Chartier (1990), allied to the concept of solidarity (Rorty apud Assis, 2013) and the ideia of experience (Larrosa, 1994).
\end{abstract}

Keywords: Experimental classes. Curricular innovation. Modern math.

\section{CURRÍCULOS EXPERIMENTALES BAHIANA Y EL DESAFÍO DE LA QUEBRA DE}

PARADIGMAS: del programa de matemáticas para la práctica escolar en las

$$
\text { décadas de } 1960 \text { y } 1970
$$

\section{RESUMEN}

Las clases experimentales baianas fueron parte del proyecto de modernización de la enseñanza desarrollado durante las décadas de 1960 y 1970. Coordenadas por el CECIBA en época de Dictadura Militar en Brasil, cumplieron importante meta de difundir una propuesta de enseñanza (de Matemática) más innovadora, que se refiere a los contenidos y métodos de enseñanza utilizados. Las experiencias realizadas en diferentes escuelas de Salvador fueron escenarios de pruebas de nuevos programas y estrategias de enseñanza, movilizando saberes a enseñar y para enseñar (Hofstetter, Valente, 2017) en aquel contexto de experimentación pedagógica. Estos saberes, oriundos principalmente de cursos de perfeccionamiento para profesores, ofrecidos por el CECIBA, fueron analizados a partir de las narrativas disponibilizadas en entrevistas semiestructuradas proporcionadas por profesores y alumnos involucrados en la experiencia del Colegio Estadual Luiz Pinto de Carvalho. En este artículo, por lo tanto, como las

Revista Exitus, Santarém/PA, Vol. 9, № 5, p. 243 - 270, Edição Especial 2019. 
clases experimentales baianas, constituidas por una iniciativa de transformación curricular a partir de la institucionalización de la Matemática Moderna, representaron un período de avances en la enseñanza (de Matemáticas) con repercusiones importantes en la vida de los personajes involucrados. Se trata de una investigación cualitativa, que toma como referenciales la perspectiva de historia cultural de Chartier (1990), aliada a la concepción de solidaridad (Rorty apud Assis, 2013) ya la idea de experiencia (Larrosa, 1994).

Palabras clave: Clases experimentales. Innovación curricular. Matemáticas Modernas.

\section{O ENSINO DE MATEMÁTICA EM ÉPOCA DE DITADURA MILITAR NA BAHIA}

Inspirados pela canção Pra não dizer que não falei das flores (1968), do cantor e compositor Geraldo Vandré, iniciamos este artigo que faz uma retomada ao período longo de forte repressão, desmandos e violência na história do Brasil, por conta da Ditadura Militar (1964-1985). Toda e qualquer expressão de opinião ou comportamento que se desencontrasse dos interesses militares na educação, nas artes e na cultura de modo geral eram punidas fortemente, num modelo de governo em que as decisões ocorriam através de imposições, decretos e atos institucionais.

Ainda que, se fazendo um grande esforço para "remar contra maré" e ideologias militaristas, seja possível identificar avanços na produção e desenvolvimento cultural, na educação, desse modo, destacaremos um aspecto específico: a difusão do projeto de classes experimentais na Bahia, mais especificamente em Salvador.

Algumas experiências inovadoras educacionais marcaram um processo de modernização do ensino (de Matemática) no Brasil, iniciado ainda no final do séculos XIX e que teve sua segunda fase dividida em dois momentos distintos, sendo um antes e outro depois da Segunda Guerra Mundial. A segunda fase foi, portanto, mais longa e mais intensa no país a partir da década de 1960, quando teve objetivos específicos voltados para o ensino de uma matemática escolar mais contextualizada e fácil de ser alcançada pelos alunos do ensino secundário da época.

Nesse ínterim, entre os anos de 1972 e 1975, algumas classes experimentais ainda se desenvolviam na Bahia, a partir de iniciativas 
pontuais de professores que tiveram contato com cursos e materiais didáticos produzidos pelo grupo de professores da Seção de Matemática do Centro de Ensino de Ciências da Bahia (CECIBA). Estamos nos referindo aqui àquelas classes experimentais realizadas, por exemplo, no Colégio Estadual Pinto de Carvalho, localizado numa região periférica de Salvador, onde poucas perspectivas de ascensão social se tinham, senão pela educação.

Dessa forma, em sintonia com a bandeira política dos militares, houve uma expansão educacional desordenada na capital baiana e na Bahia como um todo, o que reforça o papel da educação, da formação de professores e da produção de materiais didáticos para o crescimento do sistema educacional do país, que contribuíram com a institucionalização de saberes matemáticos no ensino secundário da época.

Entretanto, num sentido oposto aos interesses dos governantes militares do período ditatorial, essa abertura de novas instituições de ensino na Bahia permitiu que iniciativas importantes com o intuito de melhorar a qualidade e, não somente, as estatísticas do ensino de ciências e matemática no estado se propagassem. Em diferentes bairros de Salvador, professores oriundos dos cursos de aperfeiçoamento, oferecidos pelo CECIBA, difundiram pela capital baiana, saberes matemáticos que não se costumavam apresentar nos programas de formação anteriores, a partir de uma maneira diferente e inovadora de ensinar matemática (VALENTE, 2017).

A nova História Cultural se interessa tanto pelos mecanismos de produção dos objetos culturais, como também pelos seus processos de recepção, que de um modo ou de outro, também são formas de produção, em uma associação importante ao conceito de apropriação ${ }^{3}$. É possível destacar, também, que a ideia de "campo" utilizada por Roger Chartier, a partir da concepção de "microcosmo social" de Pierre Bourdieu são relevantes para discussão acerca do campo educacional como locus de

\footnotetext{
${ }^{3} \mathrm{Em}$ Chartier, apropriação é dada como uma definição do consumo cultural a partir de uma operação de produção, ou seja, as maneiras de se utilizar uma produção cultural também produzem novos elementos culturais.
} 
disputas por legitimidade, onde circulam diferentes discursos e bens culturais. ${ }^{4}$

Essas concepções da nova História Cultural, mais especificamente, as ideias daquela vertente representada por Chartier, ajudaram a enxergar as classes experimentais como mais um elemento fundamental no processo de institucionalização da Matemática Moderna na Bahia, já que se trata da implementação (implantação, desenvolvimento e consolidação) de certas atividades científicas num contexto específico (espaço e tempo histórico). ${ }^{5}$

Nesse sentido, vale a pena trazer à discussão a perspectiva de solidariedade associada à produção científica, apresentada por Richard Rorty, que nos permite compreender o ensino de ciências (e matemática), a partir da sua proposta curricular, como um instrumento do processo de institucionalização de saberes e práticas de ensino.

Embora cientistas vejam a si mesmo como portadores da racionalidade enquanto objetividade, eles, na prática, exercem com grande êxito a racionalidade enquanto solidariedade - "a ciência é um modelo de solidariedade humana" (RORTY, 2002, p. 61).

Nesse aspecto, nos propomos a refletir aqui sobre as seguintes questões: de que maneira esta solidariedade, no sentido de Rorty, aparece no ensino de Matemática das classes experimentais baianas, durante as décadas de 1960 e 1970? E mais: como temáticas ausentes na formação inicial dos professores passaram a integrar os programas de (matemática) e suas estratégias de ensino? Por fim, como esses novos saberes foram apropriados pelos alunos das classes experimentais e como isso repercutiu em suas vidas?

A partir desses três eixos de discussão, este artigo propõe uma análise histórica sobre a relevância das classes experimentais, dentro de um

\footnotetext{
${ }^{4}$ Nesse sentido, para a existência e funcionamento de um campo específico, é preciso haver interesses fundamentais compartilhados, que promovem tanto disputas quanto acordos. Temos aqui, portanto, a Matemática Moderna como o "campo intelectual" em constituição e o "microcosmo social" seriam algumas escolas de Salvador.

${ }^{5}$ Este entendimento de institucionalização apresentado baseia-se em FIGUEIRÔA, S. F. de M. As ciências geológicas no Brasil: uma história social e institucional, 1875 - 1934. São Paulo: HUCITEC, 1997. p. 24.
}

Revista Exitus, Santarém/PA, Vol. 9, N 5, P. 243 - 270, Edição Especial 2019. 
contexto de modernização do ensino (de Matemática), na constituição da índole e personalidade dos estudantes, considerando os diferentes saberes envolvidos na prática educativa dos professores das classes experimentais, identificados a partir dos registros e materiais históricos localizados, principalmente, livros e cadernetas escolares da época, além dos depoimentos fornecidos por personagens envolvidos na experiência do Colégio Estadual Luiz Pinto de Carvalho.

\section{Panorama baiano: aspectos socioeconômicos, políticos e culturais}

Alguns aspectos do cenário socioeconômico e político baiano podem ser mencionados aqui na tentativa de identificar sua influência no percurso das ações educacionais desenvolvidas naquele período, com destaque para as classes experimentais. Durante a década de 1960, a Bahia passou por três governos: o de Juracy Magalhães (1959-1963), o de Lomanto Júnior (1963-1967) e o de Luiz Vianna Filho (1967-1971), sendo que, neste último governo, a Secretaria de Educação e Cultura foi assumida por Luiz Navarro de Brito (1967-1969), José Duarte de Araújo (1969-1970) e Edivaldo Machado Boaventura (1970-1971).

Foi, exatamente, nesta época que a cidade de Salvador passou por um processo de transformação e urbanização, deixando para trás características de uma cidade provinciana, o que já havia se iniciado, ainda que lentamente, desde os anos de 1930, em outras regiões e cidades do país. Houve, portanto, um considerável aumento da população, acompanhado de crescimento da economia, expansão urbana e modificação da vida cultural da cidade.

O comércio era uma atividade forte dentro da cidade até os anos de 1950, dividido em regiões específicas: nas principais ruas da Cidade Alta, localizavam-se os artigos mais sofisticados, enquanto que o comércio mais popular era mais intenso nas vias de acesso aos bairros também mais populares, como a Baixa dos Sapateiros. Vale ressaltar, ainda, que o porto favorecia o comércio estabelecido com outros estados e países. 
A distribuição da população na cidade também tinha relação com a questão econômica, sendo que as famílias mais abastadas residiam ao longo da Avenida Sete de Setembro, nos bairros Campo Grande, Canela, Graça e Nazaré, enquanto que a classe média situava-se em bairros como Amaralina, Rio Vermelho, Brotas, Barbalho, Roma e Itapagipe. E, finalmente, a população menos favorecida da cidade, localizava-se na região da Liberdade, Baixa dos Sapateiros e Federação.

Até a década de 1950, havia poucas instituições de ensino secundário, não somente em Salvador, mas em toda Bahia, sendo o Colégio Estadual da Bahia, mais conhecido como Central, uma das mais importantes e conceituadas. ${ }^{6}$ Esse baixo número de instituições ressalta a necessidade de ampliação do sistema educacional baiano. A partir desse período e com as importantes intervenções de Anísio Teixeira, enquanto secretário do governo, essa situação começou a mudar e outras instituições foram sendo inauguradas, paulatinamente, em diversas áreas da capital baiana e, posteriormente, no interior do estado (DIAS, 2011, p. 2).

Esta, inclusive, passaria a ser uma das justificativas veiculadas para a crise que o Central começaria a enfrentar a partir dos anos de 1970, já que, apesar do prestígio, historicamente, constituído pela instituição, a procura pelos estudantes diminuiria diante da oferta de vagas em colégios mais próximos de suas residências, o que não procede diante de estatísticas, que apontavam a demanda por mais instituições de ensino em Salvador e na Bahia de modo geral.

A vida cultural e a boemia foram estimuladas pela configuração e dimensões da cidade. A descoberta do petróleo na Bahia e o cultivo do cacau no sul do estado são também prováveis razões para o desenvolvimento da cidade nessa época, após anos de estagnação. Porém, nem todos os aspectos foram positivos: a parcela mais pobre da população se concentrou nas áreas periféricas da cidade, no formato de

'Além do Central, podem ser citados o Instituto Central de Educação Isaías Alves (ICEIA) e as Escolas Normais de Feira de Santana e de Caetité.

Revista Exitus, Santarém/PA, Vol. 9, № 5, p. 243 - 270, Edição Especial 2019. 
invasões, com o objetivo de atrair ou expandir a infraestrutura existente na cidade para aquelas regiões.

Além da intensificação da urbanização, é na década de 1960 que vai acontecer o processo de industrialização do Nordeste com os incentivos da SUDENE e, na Bahia, isso se concretiza com a criação do Centro Industrial de Aratu (CIA) em 1967, dando mais um impulso para o desenvolvimento da capital. E, no final da década de 1970, houve a implantação do Pólo Petroquímico de Camaçari, que pode ser considerado como mais um componente propulsor do desenvolvimento do estado.

Sendo assim, num estado que se encontrava em processo de industrialização, era consenso entre os educadores da época, a necessidade de instituir uma escola capaz de ensinar aos alunos a pensar e atuar, satisfatoriamente, em um mundo em transformação e essa discussão esteve presente nos principais debates politicopedagógicos da época.

É importante destacar que nesse período, a política educacional baiana passou a ser pensada como integrante dos planos globais, conduzidos pelo lema "Segurança e desenvolvimento" dos governantes militares e que tinham no binômio "educação e desenvolvimento" o eixo principal de suas políticas públicas. Tais políticas, entretanto, não podem ser analisadas de maneira única, visto que os anos de ditadura militar no Brasil não representam um período hegemônico de transformações (CUNHA, 2007).

Na busca por soluções para os problemas educacionais do estado e que fossem condizentes com as mudanças enfrentadas pela sociedade na década de 1960, o governo da Bahia, em dois anos, propôs duas estratégias importantes: o Plano de Emergência e Plano Integral de Educação e Cultura (PIEC). O primeiro gerou a aprovação da Lei Orgânica do Ensino (lei $n^{\circ}$ 2.463/67), a Reforma Administrativa da SEC (lei n ${ }^{\circ}$ 2.464/67) e o Estatuto do Magistério Público da Bahia (lei $n^{\circ} 2.521 / 68$ ); enquanto o segundo lançou propostas de intervenção em áreas pouco assistidas, principalmente, no que tange à formação de professores, a fim de melhorar a qualidade do ensino e a quantidade de matrículas nos diversos níveis (BRITTO, 1991).

Revista Exitus, Santarém/PA, Vol. 9, № 5, p. 243 - 270, Edição Especial 2019. 
A partir da ampliação da rede escolar com o PIEC, a Bahia apresentou crescimento considerável no número de matrículas no $1^{\circ}$ e $2^{\circ}$ graus na capital e, principalmente, no interior do estado. Inclusive, houve aumento expressivo também no ensino superior, visto que foram instaladas, pelo menos, quatro novas Faculdades de Educação no interior do estado (em Feira de Santana, Jequié, Vitória da Conquista e Alagoinhas), que já haviam sido criadas desde 1962 (lei n 1.802/62) (BOAVENTURA, 2009).

\section{A pesquisa: os materiais e as narrativas}

A construção de um trabalho historiográfico de investigação, a partir de episódios ocorridos em instituições escolares não se resume em relatar a história de uma determinada escola. Trata-se, dentre outras possibilidades, da recuperação das histórias a partir das memórias dos sujeitos envolvidos e dos dados localizados num levantamento documental e/ou iconográfico, na tentativa de tecer um tapete da história (GINZBURG, 2007).

O ofício do historiador, questionado pela perspectiva da Escola dos Annales7, tal como a legitimidade das fontes ditas oficiais, permite considerar a interdisciplinaridade como possivel na investigação histórica, apresentada numa perspectiva epistemológica em que prova (verdade provável e documental) e retórica (argumentação) caminham juntas (MARTINS, 2012).

Com esta concepção, o historiador busca pelos elementos que tecem os fatos, já que a verdade é entendida como conhecimento, num trabalho de localização e interpretação de fontes escritas e/ou orais. E, portanto, temas que já tenham sido bastante explorados podem promover novas descobertas e novas conclusões, a partir de um novo imaginário social, de uma nova narrativa histórica.

\footnotetext{
7 Trata-se de um movimento surgido na França, no século XX, com a publicação de uma revista que tinha o objetivo principal de questionar os modos de fazer história até então. No decorrer dos anos, a revista fundada por Marc Bloch e Lucien Febvre se tornou símbolo dessa nova corrente historiográfica, que substituiu uma visão positivista da história por análise de processos de longa duração, dando início a uma história das mentalidades. Vale ressaltar ainda que a Escola dos Annales passou por quatro gerações, com representantes e características específicas para cada uma delas, e continua até hoje dando contribuições marcantes para a historiografia. C.f.: BARROS, 2005.
} 
Este artigo, portanto, se constitui em um dos desdobramentos da tese de Pinheiro (2017), reconstruídos a partir de seus resultados e dialogando com Assis (2013) e Barzano (2016), que contribuem para um olhar analítico voltado para a filosofia e o campo do currículo.

Dessa forma, foi desenvolvido o cruzamento de informações obtidas nos arquivos da Faculdade de Educação, da Universidade Federal da Bahia (cadernetas das classes experimentais, relatórios do CECIBA, avaliações e pastas de alunos) e de algumas escolas estaduais de Salvador, das quais destacamos o Colégio Estadual Luiz Pinto de Carvalho, em virtude dos fortes indícios localizados acerca do desenvolvimento de classes experimentais naquela instituição.

Do ponto de vista das fontes orais, destacamos a que se refere aos depoimentos de ex-alunos e professores que participaram da experiência naquele colégio, os quais foram coletados a partir da realização de entrevistas semiestruturadas (através de questões norteadoras) que foram transcritas (textualizadas). Esses depoimentos foram confrontados com cadernetas e livros didáticos, utilizados durante o desenvolvimento das atividades, que confirmaram a utilização de conteúdos e métodos de ensino inspirados pelo movimento de modernização de ensino (de matemática) e foram analisados em consonância com uma abordagem qualitativa.

\section{PROGRAMAS DE MATEMÁTICA MODERNA EM ESCOLAS DE SALVADOR}

O ensino ginasial se estabeleceu nacionalmente, a partir da Lei Orgânica do Ensino Secundário em 1942 (Decreto-lei n 4.244/42), também conhecida como Reforma Capanema, em homenagem ao então Ministro da Educação e Saúde, durante a Era Vargas (1930-1945), Gustavo Capanema Filho. A principal marca dessa lei foi a reestruturação do ensino secundário, que passou a ser dividido em dois ciclos: o ensino ginasial (4 anos) e o ensino colegial ( 3 anos), podendo este último ser de dois tipos, 
quais sejam, o clássico (foco no estudo das línguas) ou científico (foco no estudo das ciências) .8

De acordo com essa lei, foram estabelecidos os seguintes objetivos para o ensino secundário: formar a personalidade integral dos adolescentes, em continuidade à formação oferecida no ensino primário; acentuar e elevar a consciência patriótica e humanística dos estudantes e, por fim, oferecer formação intelectual geral como base para estudos mais avançados. É interessante notar, nesse sentido, que a educação estava a serviço da nação, proporcionando o desenvolvimento de habilidades e mentalidades correspondentes aos diversos papéis das diferentes classes sociais.

No que se refere aos programas específicos para cada disciplina, estava prevista nesta lei, a constituição de comissões, designadas pelo Ministério da Educação, que seriam responsabilizadas por sua elaboração. Estes programas deveriam ser caracteristicamente simples, claros e flexíveis, apresentando o sumário da matéria e as diretrizes essenciais para cada disciplina.

De maneira bastante direta, a referida lei impactou o ensino de Matemática, visto que o decreto-lei de 1942 previa a criação de comissões para elaboração dos programas de ensino de cada disciplina dos dois ciclos, tendo Euclides Roxo como integrante da área de Matemática. Apesar de defender o ensino simultâneo dos diversos ramos da matemática em cada série, Roxo conseguiu introduzir seu ponto de vista apenas no que diz respeito às questões metodológicas dos programas.

Após discussões e alterações, os programas do ensino ginasial são expedidos pela Portaria Ministerial $\mathrm{n}^{\circ} 170$, de 11/07/1942, enquanto os programas do segundo ciclo só foram expedidos pela Portaria Ministerial $n^{\circ}$ 177, de 16/03/1943. Esses programas e a Reforma Capanema de maneira geral permaneceram em vigor até 1961, quando foi promulgada a primeira

\footnotetext{
${ }^{8}$ Anteriormente, o ensino secundário dividia-se em ensino fundamental (5 anos) e ensino complementar (2 anos). C.f.: DASSIE, B. A. Euclides Roxo e a constituição da Educação Matemática no Brasil. Rio de Janeiro, 2008. 274f. Tese (Doutorado em Educação) - PUC/RJ, 2008.
}

Revista Exitus, Santarém/PA, Vol. 9, № 5, p. 243 - 270, Edição Especial 2019. 
LDB. Mas, com relação ao ensino de Matemática, especificamente, o impacto vai dar-se apenas com a disseminação das concepções de modernização do ensino nesse mesmo período (DASSIE, 2008).

As produções de livros didáticos de Matemática do grupo de professores da Bahia, que atuaram no CECIBA durante o período de existência desse Centro (1965-1969), tiveram forte influência das ideias de modernização do ensino de Matemática, amplamente difundidas pelo Brasil nesse período. Para promover a institucionalização da Matemática Moderna, foram inseridos alguns conteúdos nos programas de cada série do ensino ginasial, que tinham relação com teorias estruturantes da matemática, de base bourbakista, mas que até então, não faziam parte dos currículos escolares do ensino secundário na Bahia?.

As coleções originaram-se das apostilas de aulas produzidas pelo grupo de professoras do CECIBA, passando por modificações no decorrer dos anos, inclusive na denominação; inicialmente, chamada de Matemática Moderna, posteriormente, de Matemática, e nas últimas edições, de Ensino Atualizado de Matemática. Cada coleção dessas possuía características e perfis de ensino de Matemática distintos, ainda que tivessem sido produzidas pelo mesmo grupo de professores de Matemática ligados ao CECIBA.

A coleção Matemática, especificamente, chama a atenção pela metodologia utilizada na organização dos temas. A distribuição dos conteúdos dava-se por fichas e o professor poderia planejar seu trabalho, a partir do estudo de uma média de 30 a 40 fichas por série, de modo a cumprir os respectivos programas, integralmente, numa proposta de ensino baseada na adequação do conteúdo ao tempo disponibilizado para cada aula, o que se apresenta na tabela a seguir:

\footnotetext{
9Trata-se da segunda fase do Movimento da Matemática Moderna (MMM), analisado em dois momentos diferentes: anterior e posterior a II Guerra Mundial, compreendendo objetivos específicos em cada um deles. A influência do grupo Bourbaki é identificada com maior ênfase no segundo momento do processo de modernização do ensino de matemática. Na Bahia, a repercussão disso no ensino secundário se deu mais intensamente a partir da criação do CECIBA (1965) por um grupo de professoras coordenadas por Martha Dantas e Omar Catunda.
} 
QUADRO: Distribuição dos conteúdos matemáticos por livro/série

\begin{tabular}{|c|c|c|c|}
\hline Matemática 5 & Matemática 6 & Matemática 7 & Matemática 8 \\
\hline $\begin{array}{l}\text { Conjuntos (5 fichas); } \\
\text { Relações (2); Aplicação } \\
\text { (1); Produto cartesiano (1); } \\
\text { Números naturais (7); } \\
\text { Números primos (1); MMC } \\
\text { (1); Fração (10); Números } \\
\text { decimais (5). }\end{array}$ & $\begin{array}{l}\text { Razão (2 fichas); } \\
\text { Grandezas diretamente } \\
\text { proporcionais (2); } \\
\text { Grandezas inversamente } \\
\text { proporcionais (2); } \\
\text { Proporção (6); } \\
\text { Porcentagem (2); Juros (1); } \\
\text { Números inteiros relativos } \\
\text { (14); Equação do } 1^{\circ} \text { grau } \\
\text { (3); Tradução algébrica de } \\
\text { uma expressão (1); } \\
\text { Problemas do } 1^{\circ} \text { grau (2); } \\
\text { Sistemas de equação do } \\
1^{\circ} \text { grau com duas } \\
\text { incógnitas (5); Problemas } \\
\text { do } 1^{\circ} \text { grau com duas } \\
\text { incógnitas (1); } \\
\text { Desigualdades (1); } \\
\text { Inequação do } 1^{\circ} \text { grau (3) }\end{array}$ & $\begin{array}{l}\text { Raiz quadrada (5 fichas); } \\
\text { Dízimas periódicas (1); } \\
\text { Números reais (4); } \\
\text { Expressões algébricas } \\
\text { racionais (5); Translação } \\
\text { (2); Vetores (2); Simetria } \\
\text { (1); Retas/planos (4); } \\
\text { Ângulos (3); } \\
\text { Triângulo/Paralelogramo } \\
\text { (2); Homotetia (3); } \\
\text { Teorema de Tales (1); } \\
\text { Trapézio (1); Simetria Axial } \\
\text { (2); Figuras simétricas (1); } \\
\text { Transporte de figuras (1); } \\
\text { Medida de ângulo (1); } \\
\text { Propriedades, } \\
\text { Congruências de } \\
\text { triângulos (4); } \\
\text { Perpendiculares e } \\
\text { oblíquas (1). }\end{array}$ & $\begin{array}{l}\text { Radicais (7 fichas); } \\
\text { Equação do } 2^{\circ} \text { grau (8); } \\
\text { Equação biquadrada } \\
\text { (1); Equações irracionais } \\
\text { (2); Círculo/Rotação (7); } \\
\text { Retas concorrentes no } \\
\text { triângulo (2); Triângulos } \\
\text { semelhantes (2); } \\
\text { Relações métricas/ } \\
\text { trigonométricas (6); } \\
\text { Polígono convexo (1); } \\
\text { Polígonos regulares (4); } \\
\text { Área de polígono } \\
\text { regular (1); } \\
\text { Comprimento do círculo } \\
\text { (1); Área do setor } \\
\text { circular (1). }\end{array}$ \\
\hline Total = 33 fichas & Total $=47$ fichas & Total $=45$ fichas & Total $=43$ fichas \\
\hline
\end{tabular}

Fonte: Pinheiro, 2017, p. 56.

A partir dessa distribuição dos conteúdos nesta coleção, é possível notar que os temas relacionados à álgebra e à aritmética se apresentavam em todos os volumes, mas o que mais chama a atenção é a presença de conteúdos relacionados à geometria em cada um deles, inclusive no primeiro volume, que se dedicou a discutir, inicialmente, a temática dos conjuntos e utiliza elementos geométricos para isso. Essas são características marcantes da proposta de inovação curricular difundida pelo MMM, que permaneceram no programa de Matemática da Bahia, mesmo após o enfraquecimento do movimento nos anos de 1970 (PINHEIRO, 2017, p. 57).

A perspectiva filosófica rortiana permite enxergar as contribuições do ensino de ciências e matemática no Brasil no sentido de incentivar o rompimento de estruturas curriculares rígidas que ainda resistem e se apresentam em práticas pedagógicas. Utilizando essa linha de pensamento neopragmática, é possível reafirmar que:

A crença de que todos os homens desejam a verdade, juntamente com a de que a verdade corresponde à realidade e que, por fim, essa teria uma natureza, é que alimenta o desejo de se fundar a solidariedade na objetividade (ASSIS, 2013, p. 84). 
Entretanto, é importante ressaltar que o entendimento de uma "racionalidade enquanto objetividade" difere da "racionalidade enquanto solidariedade" para os cientistas (ASSIS, 2013, p. 94). E mais, Kleyson Assis nos aponta que "optar pelo segundo tipo e esquecer a ideia de que podemos estabelecer critérios atemporais através dos quais se pode medir o progresso" é recomendável para a compreensão mais ampla da referida solidariedade presente nos currículos escolares em determinados contextos sociais.

Sobre a solidariedade nas classes experimentais, concretizou-se, por exemplo, na relação da professora Emma com seus alunos, mas, principalmente, na relação dos alunos entre si, visto que não havia diferenciação da parte deles, seja com relação aos integrantes das classes experimentais entre si, seja entre estes e os que não integravam as classes experimentais, mesmo ambos os lados tendo consciência das vantagens, em termos de atualização do aprendizado, de fazer parte do grupo de alunos que participavam da experiência.

Como "educação" soa um tanto prosaico demais e "Bildung" um tanto estrangeiro demais, irei usar "edificação" para representar esse projeto de encontrar modos novos, melhores, mais interessantes, mais fecundos de falar (RORTY, 1994, p. 354).

Numa perspectiva de currículo de ciências e matemática em que há combinação com concepções como a de solidariedade, é possível identificar inserção, por exemplo, de valores importantes no processo formativo dos estudantes, o que revela e caracteriza, portanto, o ensino como um processo para além da instrução meramente conteudista, visto que proporciona experiências de aprendizagem e desenvolvimento para os estudantes que ultrapassam os limites do programa disciplinar.

Associar essa linha de pensamento às classes experimentais do Colégio Pinto de Carvalho, por exemplo, só reforça, a partir da análise dos relatos e narrativas dos professores e estudantes, a importância dessa linha de trabalho na formação da identidade dos personagens envolvidos na experiência. Em se tratando dos professores, esta é uma referência à 
constituição de uma identidade profissional. Por outro lado, no que tange aos estudantes, trata-se de contribuir para construção de uma consciência cidadã.

\section{Saberes, formação dos professores e seus princípios filosóficos}

Os currículos de ciências e matemática implementados nas classes experimentais baianas, a partir dos cursos, livros e reflexões propostos pelo grupo de professores do CECIBA, com objetivo de renovar o ensino dessas disciplinas escolares no ensino secundário, de acordo com a LDB de 1971, representaram uma tentativa de difusão das orientações e escolhas profissionais desses professores, determinadas politicamente. Entretanto, os registros de suas práticas nos remetem a uma análise dos saberes envolvidos nesse processo de ensinar e aprender ciências e matemática nas classes experimentais baianas.

Quando olhamos, separadamente, para os saberes a ensinar e para ensinar (HOFSTTETER; VALENTE, 2017, p. 207) é possível pensarmos em diferentes etapas do processo de formação docente e dividi-lo em três momentos, a partir dos seguintes princípios: racionalidade técnica (modelo $3+1$ ), racionalidade prática e racionalidade reflexiva (SCHÖN, 1983).

No modelo baseado na racionalidade técnica, temos três anos de uma formação técnica (teórica) e um ano de disciplinas pedagógicas, incluindo as de prática de ensino. Nesse modelo de formação há uma preparação do profissional de educação, a partir de conteúdos científicos e/ou pedagógicos importantes para sua prática. No modelo de base na racionalidade prática, implementado a partir dos anos de 1960, a formação dos futuros professores se estrutura a partir da prática reflexiva. Tinha-se produção de conhecimento, a partir do fazer e da reflexão sobre o que foi feito, criticado pelo risco de supervalorização da prática em detrimento da teoria.

Na década de 1970, tivemos o modelo com base na racionalidade reflexiva ou filosofia da práxis, com ênfase na reflexão crítica, que propõe uma formação docente, a partir de um arsenal de experiências teórico- 
prático e da valorização da pesquisa no ensino secundário. Entretanto, tratando-se de professores que já atuavam no ensino de matemática nesse período, foi necessário desenvolver estratégias de aplicação de saberes a ensinar e para ensinar a partir do trabalho nas classes experimentais.

Nesse contexto de ensino, podemos destacar as experiências do Colégio Estadual Pinto de Carvalho, conduzidas pela professora Emma Burlacchini, que teve oportunidade, anteriormente, de fazer alguns dos cursos de aperfeiçoamento de professores secundários do CECIBA e, assim, se aproximar da Matemática Moderna em evidência naquele período.10

Na época, já tinha até mudado de prédio o colégio... ela sugeriu, quando olhou minha ficha e viu que eu ensinava num colégio de periferia, lá em São Caetano. Ela me propôs... se eu gostaria de fazer uma experiência para ver se os alunos daquela área conseguiam fazer... aceitar a matemática desse jeito. A partir daí, eu conversei com o diretor e ele aceitou. Se eu não me engano, teve um ano que uma turma começou, mas depois não deu certo. Ai, quando a gente "tomou pé" mesmo e fez essa turma... A escolha... ele tirou duas turmas que já estavam formadas, essas ficaram como turmas experimentais, A e B. ${ }^{11}$ (PINHEIRO, 2017, p. 77).

Dessa forma, seguindo a sugestão da professora Martha Dantas, as duas classes experimentais, iniciadas no Colégio Pinto de Carvalho, representaram um marco bem sucedido na história daquela instituição e, além disso, na trajetória dos alunos que participaram daquela experiência inovadora no contexto baiano. Isso quer dizer que, mesmo sendo de maneira pontual e paulatina, a semente do ensino de matemática mais inovador se disseminava por diferentes escolas da capital da Bahia, possibilitando novas perspectivas de crescimento pessoal e cultural para os personagens envolvidos naquela experiência específica, de modo a agregar estes privilégios a quem não os tinha.

Podemos pensar em experiência a partir de diferentes perspectivas: por exemplo, no sentido de cunho antropológico da ciência, de Bruno

10Professora Emma Burlacchini fez os cursos de Elementos de Lógica Simbólica (1966); Introdução à teoria dos conjuntos (1966), Principais estruturas algébricas (1966); Matemática Moderna - $1^{\circ}$ Estágio (1967); Matemática Moderna - 2 Estágio (1967), dos quais ela guardou os respectivos certificados.

"Transcrição de trecho da entrevista com Emma Burlacchini, ex-professora do Colégio Estadual Luiz Pinto de Carvalho, obtida em 14/03/2017. 
Latour, ou numa linha de pensamento mais pragmática da educação, referenciada em John Dewey. Entretanto, aquela que adotaremos aqui corresponde a uma ideia de experiência amparada na filosofia de Jorge Larrosa ${ }^{12}$, que se refere ao saber produzido a partir da prática. De modo que, essa perspectiva amplifica o grau de importância das classes experimentais baianas naquele contexto específico da década de 1970, quando as experiências eram cada vez mais pontuais diante da demanda de modernização do ensino existente e dependiam de iniciativas isoladas dos professores, ou seja, sem acompanhamento direto do CECIBA. Além disso, para o desenvolvimento de trabalhos como o das classes experimentais, era determinante a manutenção do interesse dos professores que as iniciavam.

\section{CURSOS, MATERIAIS DIDÁTICOS E SABERES: AGENTES DIFUSORES DE UMA EXPERIÊNCIA CURRICULAR INOVADORA}

Dentro do contexto de renovação do ensino secundário, já apontado aqui, O CECIBA surge em 1965 como uma iniciativa importante, a fim de modernizar o ensino de Ciências (Física, Química e Biologia) e Matemática, especificamente, a partir da oferta de capacitação e treinamento de professores que passariam a atuar ou já atuavam no ensino dessas disciplinas escolares, considerados em situação de defasagem em todo país e, por isso, passaram a ser priorizadas. ${ }^{13}$

Além do trabalho voltado para o treinamento e capacitação de professores, o já citado grupo de professores, durante a atuação no CECIBA, desenvolveu outras ações relevantes, sendo importante mencionar a produção de materiais e livros didáticos (LIMA et al., 2013). Essa produção inovadora foi testada nas classes experimentais baianas e aprimorada posteriormente.

\footnotetext{
${ }^{12}$ Experiência, à luz de Jorge Larrosa, pressupõe que um acontecimento externo alcance o sujeito de tal forma que produza efeitos no entendimento e no sentimento acerca do episódio vivido. E o ato de narrar para o outro a experiência exige uma etapa de reflexão anterior. Assim, apresenta-se uma perspectiva que aponta para a importância do saber da prática, da experiência, aqui relacionado às classes experimentais baianas.

13Outros cinco centros, com a mesma finalidade, foram criados em outras regiões estratégicas do país, são eles: CECIGUA, CECISP, CECIMIG, CECIRS, CECINE.
} 
Sendo assim, em algumas instituições de ensino de grande relevância para o cenário educacional baiano à época, conforme dito anteriormente, foram desenvolvidas experiências pontuais de implantação de novas abordagens para o ensino de algumas disciplinas escolares, como Física, Química, Biologia e Matemática, sob a orientação do CECIBA, além da experiência estruturada realizada no Central (RAMOS, 2012).

O trabalho desenvolvido, pontualmente, nas classes experimentais de colégios estaduais de Salvador, mais especificamente nas turmas voltadas para o ensino de Matemática, tinha como meta principal verificar a viabilidade de utilização de um novo método de ensino, o da Matemática Moderna, a partir da produção didática da Seção Científica de Matemática do CECIBA, o que posteriormente deveria ser ampliado e difundido.

De acordo com a documentação localizada e analisada (PINHEIRO, 2017), identificamos a tentativa de realização de uma experiência, sob a orientação do CECIBA, em 1967. Entretanto, vale ressaltar que a referida turma do Colégio Estadual Luiz Pinto de Carvalho, iniciada neste período, não foi adiante por razões desconhecidas. Só na década de 1970, a experiência foi retomada com êxito nesta instituição de ensino.

Nesse sentido, as narrativas fornecidas pelos personagens envolvidos podem ser úteis no processo de investigação ou formação, ou seja, trata-se de um aporte metodológico ou didático, a depender do tipo de reflexão e análise feitas a partir da produção desse instrumento de coleta de dados. $O$ movimento dialético entre teoria e realidade, no campo da pesquisa, permite um distanciamento e aproximação constantes numa investigação por narrativas, no sentido de perceber, reformular e, de maneira mais abrangente, dar conta de uma dada realidade.

[...] o sentido do que somos depende das histórias que contamos e das que contamos a nós mesmos [...], em particular das construções narrativas nas quais cada um de nós é, ao mesmo tempo, o autor, o narrador e o personagem principal (LARROSA, 1994, p.48).

Em especial, a narrativa histórica, para ser considerada História, parte da veracidade dos fatos a serem investigados, sendo, portanto, construída a 
partir das fontes e documentos históricos, que os comprovem e, de alguma maneira, limitem a licença poética do historiador quando comparados com autores de ficção. Nessa linha de pensamento, pode-se afirmar com veemência que "ainda que o passado possa apenas ser reconstruído pela imaginação narrativa, a distância entre realidade e representação aqui é de uma natureza qualitativamente diferente daquela que opera na ficção". (KEARNEY, 2012).

Ao discutir as narrativas dos alunos e professores das classes experimentais do Colégio Pinto de Carvalho, conseguimos identificar a importância da legislação educacional, dos aspectos culturais, econômicos e políticos em que se desenvolveu aquela experiência, especificamente. No trecho a seguir, é possível identificar que as classes experimentais do Colégio Pinto de Carvalho foram desenvolvidas num período de transição no cenário educacional, provocado pelas mudanças na legislação, diante da promulgação da lei $n^{\circ} 5692 / 71$, que dentre outras alterações, reestruturou o ensino secundário em ensino de $1^{\circ}$ e $2^{\circ}$ graus.

Começou com três turmas. Nós entramos em 1972... Foi quando se instituiu a $5^{a}$ série porque antes $5^{\circ}$ ano, $1^{a}$ série ginasial. Nós entramos na $5^{a}$ série, mas nós fizemos $05^{\circ}$ ano primário e exame de admissão. Então, nós entramos nesse período de transição, da mudança da lei. Nós fizemos duas vezes a $5^{\mathrm{a}}$ série, porque, na época, o primário era obrigado fazer até o $5^{\circ}$ ano. Depois, em 1972, que mudou com a lei... me esqueci agora o número da lei... (PINHEIRO, 2017, p. 105) ${ }^{14}$.

É importante refletir acerca da informalidade dessas ações das professoras formadoras, ligadas ao CECIBA, que se multiplicaram entre outros professores de Matemática de Salvador na implementação das classes experimentais. Não houve, por exemplo, uma explicitação dos objetivos da realização daquelas experiências, nem entre os professores que desenvolveram aquelas iniciativas, nem entre os alunos que participaram do projeto.

Olha, é como eu te disse... não houve nunca nenhuma discussão dos professores, do tipo "olhem, nós estamos aplicando um projeto nessa

\footnotetext{
14 Transcrição de trecho da entrevista com Jussara Bittencourt e Aroldo Assunção, ex-alunos do Colégio Estadual Luiz Pinto de Carvalho, obtida em 16/02/2017.
}

Revista Exitus, Santarém/PA, Vol. 9, № 5, p. 243 - 270, Edição Especial 2019. 
turma experimental, que visa isso ou visa aquilo, nós temos estes propósitos..." Nunca. (PINHEIRO, 2017, p. 79) ${ }^{15}$.

Apesar de existir uma recomendação legal para desenvolvimento dessas experiências em todo o país, não houve uniformidade entre elas, já que cada uma teve características específicas. Quando tomamos o caso das experiências baianas, esse aspecto se torna ainda mais evidente, o que justifica a realização do estudo de cada uma delas em separado para melhor entendimento do processo de experimentação pedagógica como um todo.

Importante ressaltar, especificamente, sobre a experiência do Colégio Pinto de Carvalho, que foi instituída uma disciplina curricular na instituição, denominada por Matemática Complementar, a fim de desenvolver o estudo daqueles conteúdos que deveriam ser inseridos no novo programa de Matemática. A partir das mudanças legais para educação, apresentadas na nova LDB (lei n 5692/71), experimentações pedagógicas como esta puderam se desenvolver, sendo importante ressaltar o interesse da professora Emma em agregar aquela nova perspectiva curricular e teoricometodológica de ensino de Matemática à sua prática docente.

(...) para você ter uma noção: nós tínhamos dois professores de Português e dois de Matemática. Isso já era um diferencial. Tinha uma professora que trabalhava mais com gramática e outra, mais com textos e literatura. Na matemática, tinha a Matemática Básica, que era mais de cálculos e tinha a Matemática Complementar, que eram essa matemática mais moderna, que a Emma que aplicava com a gente, você se lembra? (PINHEIRO, 2017, p. 77-78) ${ }^{16}$.

Existem dois aspectos que caracterizaram fortemente a experiência do Colégio Estadual Luiz Pinto de Carvalho: um diz respeito ao clima de favorecimento dos alunos que participaram da experiência e que se instaurou na instituição, apesar de não ter havido grandes atritos entre os estudantes por conta disso. Essa ideia se consolidou nas lembranças dos alunos, que afirmaram sem reservas: "Nós éramos o centro das atenções da

\footnotetext{
15Transcrição de trecho da entrevista com Jussara Bittencourt e Aroldo Assunção, ex-alunos do Colégio Estadual Luiz Pinto de Carvalho, obtida em 16/02/2017.

16Transcrição de trecho da entrevista com Jussara Bittencourt e Aroldo Assunção, ex-alunos do Colégio Estadual Luiz Pinto de Carvalho, obtida em 16/02/2017.
}

Revista Exitus, Santarém/PA, Vol. 9, № 5, p. 243 - 270, Edição Especial 2019. 
escola e nós correspondíamos a isso, então ficamos conhecidos, marcados na escola durante muito tempo." (PINHEIRO, 2017, p. 78) ${ }^{17}$.

Entretanto, no decorrer da experiência, certo tom de hostilidade em função de um comportamento "mais livre" e cada vez mais consciente de seus direitos e responsabilidades políticas, dentro daquela instituição ensino naquele período específico, foi questionado pelo poder institucional dos seus dirigentes. A maturidade adquirida pelos estudantes no decorrer da experiência e os bons resultados nos estudos conferiu-lhes tamanho empoderamento, que gerou mudanças na organização das classes do Colégio Pinto de Carvalho, e até a incompletude da experiência no seu último ano.

Então, quando chegamos na $8^{a}$ série, o que a gente ouvia era assim "esses meninos estão ficando insuportáveis... não dá mais para permanecer todos juntos". Ai, foram... botaram assim: tinha turma até J e foram separando a gente assim... nas mais diversas turmas. (PINHEIRO, 2017, p. 78) ${ }^{18}$.

O outro aspecto, apesar de não ser exclusivo da experiência do Colégio Pinto de Carvalho, também foi considerado muito marcante pelos alunos que participaram daquelas classes experimentais: tem relação com o comportamento dos alunos, o que já tinha sido identificado antes (PINHEIRO et al., 2014). Por terem sido desenvolvidas em período de repressão, devido ao governo dos militares, o controle e a disciplina foram incutidos na sociedade de maneira geral. E, no ambiente escolar, isso não foi diferente.

\footnotetext{
Naquela época, tinha a Ditadura e nós éramos jovens demais. A nossa insubordinação era simplesmente em ter um comportamento mais livre. Não era assim... Era um comportamento irreverente (...)

Talvez até porque a gente pensasse que a gente era mesmo mais do que os outros. Que nós tínhamos um... privilégio de ser daquelas turmas experimentais (...)

Mas, isso se formou naturalmente. Não havia, por exemplo, uma hostilidade com relação às outras turmas, que não eram experimentais (PINHEIRO, 2017, p. 78-79) ${ }^{19}$.
}

\footnotetext{
${ }_{17}$ Transcrição de trecho da entrevista com Jussara Bittencourt e Aroldo Assunção, ex-alunos do Colégio Estadual Luiz Pinto de Carvalho, obtida em 16/02/2017.

${ }^{18}$ Transcrição de trecho da entrevista com Jussara Bittencourt e Aroldo Assunção, ex-alunos do Colégio Estadual Luiz Pinto de Carvalho, obtida em 16/02/2017.

${ }^{19}$ Transcrição de trecho da entrevista com Jussara Bittencourt e Aroldo Assunção, ex-alunos do Colégio Estadual Luiz Pinto de Carvalho, obtida em 16/02/2017.
} 
Essa "insubordinação" e "irreverência" dos estudantes diz muito sobre as instituições escolares de Salvador durante a Ditadura Militar, o que em certa medida, abrangeu outras regiões da Bahia nesse mesmo período. Trata-se aqui de ideologia e luta por direitos que, autoritariamente, Ihes estavam sendo usurpados. O impacto direto disso foi revolta, manifestada em passeatas de protesto, paralisações de atividades, que eram fortemente reprimidas pelos governantes militares da época.

É possível perceber, por fim, as repercussões daquela prática inovadora na trajetória dos alunos, visto que favoreceu o desenvolvimento de valores importantes na contituição daqueles indivíduos em formação, tais como respeito, tolerância e solidariedade, tanto sob um olhar educacional quanto pessoal em curto prazo, já que uma análise disso relacionada aos personagens envolvidos, em longo prazo, estrapola ao objetivo apresentado para esse artigo.

E assim... acho que a maioria daquele grupo progrediu do ponto de vista de estudar, de ganhar seu espaço no mundo (...) ninguém foi preso, ninguém virou bandido, ninguém virou traficante, ninguém virou político ladrão, sabe? Todo mundo cabeça boa, trabalhando e progredindo, formou família e se desenvolveu, foi conhecer o mundo, conhecer as coisas (...) Então, talvez sim... a experiência deu um estímulo e tenha desenvolvido em cada um a ideia... ou a prática de união e solidariedade... e o gosto pelo saber, que acho que essa seja, talvez, a diferença da escola atual... nós fomos estimulados a gostar de saber, de aprender e isso acho que é uma característica da nossa experiência do ginásio enquanto turmas experimentais (PINHEIRO, 2017, p. 69-70) ${ }^{20}$.

Num cenário político de Ditadura Militar, é difícil eleger a pior das ações de violência, mas arriscamos eleger uma bastante grave: a censura, visto que limitava a expressão de opinião de artistas, intelectuais e jornalistas nos principais meios de comunicação da época (rádio, televisão e jornais), quando não as modificava forçadamente. Quando analisamos quanta manipulação de ideias estava por trás do ato da censura, percebemos quão maliciosos foram os militares durante seus governos, ainda que seja um equívoco fazer uma análise do período ditatorial como sendo de natureza única.

${ }^{20}$ Transcrição de trechos da entrevista de Jussara Bittencourt e Aroldo Assunção, ex-alunos do Colégio Estadual Luiz Pinto de Carvalho, obtida em 16/02/2017. 


\section{APROXIMANDO-NOS DE UM FINAL}

O Brasil se caracterizava como uma sociedade em transição, no qual a população buscava oportunidades apresentadas pelo desenvolvimento econômico e, do ponto de vista educacional, tal expansão populacional nas cidades suscitava uma preparação da mão de obra que trabalharia nas indústrias, conferindo à educação escolar não só a concepção de um direito, mas também, de uma necessidade para aquele momento.

Sendo assim, a partir do percurso traçado pelos intelectuais e políticos dos anos de 1920 e 1930, que introduziram a defesa da escola pública, laica, universal e gratuita, os debates da década de 1960 e 1970 ampliaram essa discussão, propondo uma descentralização administrativa agregada à formação de técnicos profissionais da educação e, para, além disso, atribuiu-se à escola a responsabilidade de formar uma nova consciência nacional, capaz de integrar o indivíduo ao modo de vida democrático amplamente desejado.

É possível identificar na educação, portanto, os reflexos de questões políticas e econômicas pelas quais o país passou no decorrer dos anos. No período de 1955 a 1965, por exemplo, houve um aumento de incentivos do Estado para educação e cultura, o que possibilitou a ampliação da rede escolar, mesmo que de maneira ainda insuficiente diante da demanda da época.

É preciso considerar aqui, a produção de materiais e livros didáticos no Brasil, que, em geral, refletiram a filosofia do ensino de ciências e matemática em diferentes épocas, a partir dos conteúdos e metodologias abordadas. Essa produção pode ser analisada em duas fases principais: antes e depois dos anos de 1950, quando apresentou características diferentes para cada uma delas.

Até meados da década de 1950, os livros didáticos utilizados no Brasil eram traduções e adaptações de manuais europeus, com muitas informações e poucas atividades e problemas. A partir da segunda metade do século XX, houve um movimento de transformação da lógica de produção dos livros didáticos no Brasil, motivado pelo contexto político- 
econômico da Guerra Fria. Dessa forma, os livros didáticos passaram por um processo de renovação, no qual os conteúdos foram selecionados e organizados de maneira a se tornarem relevantes para a maioria das escolas brasileiras.

Conclui-se que a iniciativa do CECIBA de participar desse processo de produção de livros e materiais didáticos ganhou projeção no contexto educacional baiano, e mais especificamente, no trabalho de experimentação pedagógica associado a esse Centro, que promoveu transformações positivas no âmbito de algumas escolas baianas da época, sendo possível, portanto, afirmar que houve um processo de disseminação, para além da Escola de Aplicação, do projeto de experimentação pedagógica na Bahia.

Entretanto, esse processo de renovação da produção didática no Brasil deparou-se com uma dificuldade: o currículo padrão, que impedia a inserção de novos materiais e métodos de ensino que não estivessem de acordo com o programa proposto pelo MEC, o que foi solucionado com a LDB de 1961, devido à revogação da obrigatoriedade dos programas oficiais, oferecendo mais liberdade às escolas na escolha dos conteúdos, o que resultou na introdução dos materiais do IBECC nas escolas brasileiras.

Podemos integrar à referida discussão a ideia de solidariedade (RORTY,1994) e relacioná-la ao currículo de ciências e matemática nas décadas de 1960 e 1970, sob um ponto de vista histórico e filosófico, nos remetendo às classes experimentais de Matemática, desenvolvidas no Colégio Estadual Luiz Pinto de Carvalho, entre os anos de 1972 e 1975.

Rorty propõe uma perspectiva de conhecimento que se justifica apenas localmente (etnocentrismo), em que ao conhecimento associa-se uma dada solidariedade e à razão, conversação, tendo em vista que a correspodência crença-mundo não é dada naturalmente, mas sim, as crenças são justificadas socialmente (ASSIS, 2013, p. 82). Nesse sentido, "O conhecimento não pode ser uma questão de adequação com a realidade, e sim, de concordância entre os membros de uma determinada comunidade." (ASSIS, 2013, p. 82). 
Nessa concepção, são apontadas duas maneiras pelas quais os homens reflexivos dariam sentido às suas vidas: uma tem a ver com a história e sua relação com a comunidade e a outra "a partir da descrição de si mesmos como estando em relação imediata com a realidade nãohumana." (RORTY, 2002, p.37).

No primeiro caso tem-se com clareza, a solidariedade e no segundo, a objetividade. Dessa forma, pode-se concluir que à medida que o distanciamento dos membros de uma comunidade aumenta em direção a algo independente dela, há maior aproximação da objetividade. E, com esse olhar, analisamos a questão da solidariedade evidenciada entre os alunos e professores que participaram da experiência do Colégio Pinto de Carvalho nos anos de 1970.

Trata-se de uma das experiências inovadoras que se realizaram no processo de experimentação pedagógica na Bahia, iniciado por Martha Dantas e que, a partir dos anos de 1960, contou com a colaboração de Omar Catunda e outras professoras de matemática na constituição da Seção de Matemática do CECIBA e nos trabalhos do grupo (cursos de aperfeiçoamento de professores, materiais didáticos, eventos científicos e experiências inovadoras).

A partir da motivação de institucionalizar um novo currículo de matemática no ensino secundário, baseado na Matemática Moderna, que oferecesse condições reais aos estudantes de avançar nos estudos, qualquer que fosse a área de atuação escolhida. Em outras palavras, a proposta e as ações do CECIBA eram desenvolvidas no sentido de melhorar a qualidade do ensino na Bahia, utilizando novos programas e métodos. Mas, indo além, apresentou uma matemática mais acessivel aos estudantes secundaristas da época, instaurando uma dinâmica solidária entre eles.

Com esse raciocínio, é possível identificar na análise das narrativas feitas pelos professores e alunos que participaram, por exemplo, das classes experimentais do Colégio Pinto de Carvalho, desenvolvidas entre 1972 e 1975, como se deu a abordagem de conteúdos e temas de matemática, ausentes na formação inicial daqueles professores e quais estratégias eles 
utilizaram para contornar essa dificuldade em prol da melhoria da qualidade do ensino na Bahia.

Nas classes experimentais do colégio Pinto de Carvalho, a professora Emma teve oportunidade de compartilhar com seus alunos saberes a ensinar e para ensinar matemática. Como nesse processo de atualização dos currículos e dos métodos de ensino o foco era a Matemática Moderna para o ensino secundário, é possível que esses saberes tenham aparecido simultaneamente na prática pedagógica desenvolvida (BARZANO, 2016).

$\mathrm{Na}$ referida perspectiva de ensino inovador, as classes experimentais foram o ambiente onde as aprendizagens se concretizavam pelos testes da proposta, que produziam adequações oriundas dos resultados alcançados em cada ação, seja com relação aos livros ou métodos de ensino utilizados.

Neste artigo, desenvolvemos uma discussão histórica e filosófica acerca de currículo como tema geral, a partir das classes experimentais do Colégio Luiz Pinto de Carvalho, realizadas entre 1972 e 1975. Sendo assim, destacamos os saberes envolvidos no desenvolvimento do trabalho pedagógico da professora localizada, que disponibilizou suas narrativas acerca daquela experiência e que foram confrontadas com os relatos dos alunos e com os documentos localizados nos arquivos.

De modo geral, entre professores e alunos, há um consenso acerca dos resultados positivos alcançados com as classes experimentais, em termos de conheciementos curriculares e não curriculares, que repercutiram da melhor maneira possível na sequência da trajetória estudantil daqueles alunos. Entretanto, a única crítica que permanece diz respeito a este projeto não ter atingido a totalidade das classes baianas, tal como se pretendia inicialmente. Que interesses estariam por traz disso?

\section{REFERÊNCIAS}

ASSIS, K. R. Conhecimento e solidariedade: uma perspectiva neopragmática sobre o ensino de ciências. 2013. 152f. Tese (Doutorado em Ensino, Filosofia e História das Ciências) - Universidade Federal da Bahia/Universidade Estadual de Feira de Santana, Salvador/BA, 2013. 
BARZANO, M. A. L. Currículo das margens: apontamentos para ser professor de Biologia e Ciências. Revista Educ. foco, v. 21, n. 1, p. 105-124, 2016.

BARROS, J. A. História Cultural e a contribuição de Roger Chartier. Diálogos, DHI/PPH/UEM, v. 9, n. 1, p. 125-141, 2005.

BOAVENTURA, E. M. A construção da universidade baiana: origens, missões e afrodescendência. Salvador: EDUFBA, 2009.

BRITTO, L. N. de. Educação na Bahia: propostas, realizações e reflexões. Vol. 1, São Paulo: T. A. Queiroz, 1991. (Coleção Navarro de Britto)

CHARTIER, R. A história cultural: entre práticas e representações. Lisboa: DIFEL, 1990.

CUNHA, L. A. A Universidade reformada: o golpe de 1964 e a modernização do ensino superior. Rio de Janeiro: Francisco Alves, 2007.

\section{DASSIE, B. A. Euclides Roxo e a constituição da Educação Matemática no}

Brasil. Rio de Janeiro, 2008. 274f. Tese (Doutorado em Educação) - PUC/RJ, 2008.

DIAS, A. L. M. Uma história da educação na Bahia. In: Simpósio Nacional de História - Anpuh, XXVI, 2011, São Paulo. Anais... São Paulo: Universidade de São Paulo, 2011. Disponível em:

<http://www.snh2011.anpuh.org/resources/anais/14/1300909600_ARQUIVO_A LMD.EducacaomatematicaBahia_revisado.pdf>. Acesso em: 16 mai. 2017.

FREIRE, I. A. A. Ensino de Matemática: iniciativas inovadoras no Centro de Ensino Ciências da Bahia (1965-1969). 2009. 103 f. Dissertação (Mestrado em Ensino, Filosofia e História das Ciências) - Universidade Federal da Bahia/Universidade Estadual de Feira de Santana, Salvador/BA, 2009.

GINZBURG, C. O fio e os rastros. Verdadeiro, falso, fictício. Tradução: Rosa Freire d' Aguiar e Eduardo Brandão. São Paulo: Companhia das Letras, 2007.

GOMES, L. P. S. Entre a Exposição e a Descoberta: a coleção "Matemática" e as práticas escolares relacionadas à sua utilização no Instituto Nossa Senhora da Piedade. 2014. 147 f. Tese (Doutorado em Educação) - UNICAMP, Campinas/SP, 2014.

KEARNEY, R. Narrativa. Educação \& Realidade, v. 37, n. 2, p. 409-438, 2012.

LARROSA, J. Tecnologias do eu e educação. In: SILVA, Tomaz T. (ORG.). O sujeito da educação. Petrópolis: Vozes, 1994, p. 35-86.

LIMA, E. B.; LANDO, J. C.; FREIRE, I. A. A. A coleção didática Ensino Atualizado de Matemática: o Guia do Professor. In: Congresso Iberoamericanos de 
Educação Matemática, VII., 2013 Montevideo. Actas... Montevidéu: Colegio Seminario, 2013.

MARTINS, L. G. Tecendo fios e investigando rastros: a produção dos discursos sobre a infância. Revista Ágora, n. 15, 2012.

PINHEIRO, M. M. L. As classes experimentais de matemática e a difusão da experimentação pedagógica na Bahia durante as décadas de 1960 e 1970. 2017. $119 f$. Tese (Doutorado em Ensino, Filosofia e História das Ciências) Universidade Federal da Bahia/Universidade Estadual de Feira de Santana, Salvador/BA, 2017.

PINHEIRO, M. M. L.; LANDO, J. C.; DIAS, A. L. M. Disciplina e controle dos alunos como bases necessárias para o êxito da experimentação pedagógica nas classes-piloto de matemática do Colégio Estadual da Bahia (1966-1969). Revista Brasileira de História da Ciência, v. 7, n. 2, p. 186-202, 2014.

RAMOS, M. M. L. P. Modernização da Matemática na Bahia: a experiência com classes-piloto do Colégio Estadual da Bahia - Central (1966-1969). 2012. 155 f. Dissertação (Mestrado em Ensino, Filosofia e História das Ciências) Universidade Federal da Bahia /Universidade Estadual de Feira de Santana, Salvador/BA, 2012.

RORTY, R. A Filosofia e o espelho da natureza. Trad. Antônio Trânsito. 3. ed. Rio de Janeiro: Relume-Dumará, 1994.

RORTY, R. Objetivismo, relativismo e verdade. Trad. Marcos Antônio Casanova, 2. ed. Rio de Janeiro: Relume-Dumará, 2002.

SCHÖN, D. A. The Reflective Practitioner: how professionals think in action. London: Temple Smith, 1983.

VALENTE, W. R. A matemática a ensinar e a matemática para ensinar: os saberes para formação do educador matemático. In: HOFSTETTER, R. VALENTE, W. R. (Orgs.). Saberes em (trans) formação: tema central a formação de professores. $1^{a}$ ed. São Paulo: Editora da Física, 2017, p. 201 228.

Recebido em: 18 de setembro de 2018 Aprovado em: 03 de julho de 2019 